\title{
Who is an author? A fresh look at the rules and ethics of scientific authorship
}

John Yaphe*

A statement attributed to the American political scientist William Sayre says that academic disputes are so bitter because the stakes are so low. There are few debates as bitter among academics as the debates over authorship of scientific papers. Perhaps it would be helpful for us to review our stand on this topic as an editorial board, early in our new term as editors.

Happily we can refer to accepted published guidelines on this topic. I often look first to the British Medical Journal because their guidelines are clear and concise. ${ }^{1}$ An author is someone who has made a substantial contribution to a report. This includes the conception of the paper, the choice of methods, the collection and analysis of data, and the writing and editing of the final report. It also includes taking responsibility for what has been written once it is published. These guidelines are presented in greater detail in the Uniform Requirements for Manuscripts Submitted to Biomedical Journals: Ethical Considerations in the Conduct and Reporting of Research: Authorship and Contributorship published by the International Committee of Medical Journal Editors. ${ }^{2}$ Our journal also follows these rules and potential contributors are advised to read and respect them. ${ }^{3}$

The guidelines also state clearly who is not an author. It is not enough to have held the door open when they brought the rats into the lab for the study to be an author of that study. It is also not enough to merely secure funding, collect data, treat patients, or be the boss of a lab to guarantee a place in the list of authors. If you have performed several of these tasks as well as writing substantial parts of the final report and can take res-

*MD, Associate Professor, School of Health Sciences, University of Minho. ponsibility for what you have written, then you may be an author.

The new concept of contributorship has challenged the traditional role of authorship. ${ }^{4}$ Many journals ask for details of the role each contributor played in the conduct of the study and the publication of the report. We may consider that step in our journal too.

The order of authors can also be a thorny question. My late father, Prof. Wilfred Yaphe, who supervised the theses of many graduate students and published may studies in microbiology with teams of international collaborators used to say: "The first author is the one who writes the first draft." He knew how tough it was to get that first draft down in words. The first author has special responsibilities and enjoys special rewards as a result. The last author is traditionally the academic head of the team but this varies. Informed readers usually know who the leader of the group was.

It helps to settle questions of authors and their order in the early stages of a study. This may be recorded in the study proposal or protocol, explaining what each team member must do to become an author. Sometimes authors drop out of the list if they cease to be active or to contribute to a study. Sometimes authors are added. Recently we benefitted from valuable advice from a statistical consultant who changed the interpretation of results and the impact of a study with the application of the correct analysis. He also contributed to the re-writing of relevant sections of the methods, results and discussions to explain this analysis and the new finding. By agreement of all existing authors, he was added to the list of authors.

Giving credit to people who have done no work on a paper, like the famous head of a lab who lends his illustrious name, is one problem. Another problem is leaving out the names of people who have made a sig- 
nificant contribution. This may be a junior student and it seems unethical to do this. There are many touching anecdotes that describe the impact of this problem. ${ }^{5}$

Another problem with un-credited writers involves a potential conflict of interest. The problem of ghost writers or "guns for hire" appears to be rare in Portugal but is a problem in other countries. ${ }^{6}$ Readers deserve to know who wrote what and who takes responsibility for what has been written. If a paid author is employed to write a paper, for example at the request of a commercial funding body like a drug company, we want to know about that.

Other issues of authorship have arisen when a trainee submits a case for presentation or publication without the knowledge or consent of the trainer who is responsible for their care. A thoughtful opinion on a case of this type had been published by the ethics committee of ARSN and is worth reading and studying. ${ }^{7}$

Other ethical issues involved in publishing scientific papers such as plagiarism, duplicate publication, conflicts of interest and the effects of funding on publication are also related to authorship but are beyond the scope of this essay. We have many important topics to explore in future editorials. We look forward to your contribution to this debate to improve the quality of fa- mily medicine publications in Portugal.

\section{CONFLICT OF INTEREST STATEMENT}

The author is a member of the editorial board of RPCG, a peer-reviewed journal, and has written and reviewed for peer-reviewed journals.

\section{REFERENCES}

1. Authorship \& Contributorship. Avalilable from: http://resources.bmj. com/bmj/authors/article-submission/authorship-contributorship [accessed 05/07/2011].

2. International Committee of Medical Journal Editors [homepage on the Internet]. Uniform Requirements for Manuscripts Submitted to Biomedical Journals: Writing and Editing for Biomedical Publication. Available from: http://www.ICMJE.org [accessed 05/07/2011].

3. Conselho Editorial da Revista Portuguesa de Clínica Geral. Normas para apresentação de artigos à Revista Portuguesa de Clínica Geral. Rev Port Clin Geral 2010 May-Jun; 26 (3): 325-40.

4. Smith R. Authorship is dying: long live contributorship. BMJ 1997 Sep 20; 315 (7110): 696.

5. Jain SH. Negotiating authorship. J Gen Intern Med 2011 Jun 8 [Epub ahead of print] doi: 10.1007/s11606-011-1754-1

6. Chabner BA. Ghost writers in the sky. Oncologist 2009 Mar; 14 (3): 199200.

7. Comissão de Ética Para a Saúde da ARS Norte, IP. Parecer n. ${ }^{\circ}$ 1, 2009. Available from: http://portal.arsnorte.min-saude.pt/portal/page/portal/ARSNorte/Comiss\%C3\%A30\%20de\%20\%C3\%89tica/Ficheiros/Pa recer_CES_01_09.pdf [accessed 05/07/2011].

\section{ENDEREÇO PARA CORRESPONDÊNCIA}

yonahyaphe@hotmail.com 